\title{
Imaging findings in fetal diaphragmatic abnormalities
}

\author{
Leonor Alamo $^{1} \cdot$ François Gudinchet $^{1} \cdot$ Reto $^{\text {Meuli }^{2}}$
}

Received: 30 July 2014 / Revised: 29 April 2015 / Accepted: 17 June 2015 / Published online: 9 August 2015

(C) Springer-Verlag Berlin Heidelberg 2015

\begin{abstract}
Imaging plays a key role in the detection of a diaphragmatic pathology in utero. US is the screening method, but MRI is increasingly performed. Congenital diaphragmatic hernia is by far the most often diagnosed diaphragmatic pathology, but unilateral or bilateral eventration or paralysis can also be identified. Extralobar pulmonary sequestration can be located in the diaphragm and, exceptionally, diaphragmatic tumors or secondary infiltration of the diaphragm from tumors originating from an adjacent organ have been observed in utero. Congenital abnormalities of the diaphragm impair normal lung development. Prenatal imaging provides a detailed anatomical evaluation of the fetus and allows volumetric lung measurements. The comparison of these data with those from normal fetuses at the same gestational age provides information about the severity of pulmonary hypoplasia and improves predictions about the fetus's outcome. This information can help doctors and families to make decisions about management during pregnancy and after birth. We describe a wide spectrum of congenital pathologies of the diaphragm and analyze their embryological basis. Moreover, we describe their prenatal imaging findings with emphasis on MR studies, discuss their differential diagnosis and evaluate the limits of imaging methods in predicting postnatal outcome.
\end{abstract}

Keywords Congenital abnormality · Diaphragm · Fetus · Magnetic resonance imaging $\cdot$ Prenatal diagnosis $\cdot$ Ultrasound

Leonor Alamo

leonor.alamo@chuv.ch

1 Unit of Radiopediatrics, Department of Radiology, University Hospital Center of Lausanne, Lausanne, Switzerland

2 Department of Radiology, University Hospital Center of Lausanne, Lausanne, Switzerland

\section{Introduction}

The rate of prenatal diagnosis of diaphragmatic pathologies has increased considerably in recent years because of the generalization and technical improvements of US pregnancy screening examinations. More recently, complementary MRI studies have been included in the standard evaluation of these pathologies. A congenital diaphragmatic hernia is by far the most commonly reported anomaly and the main indication for thoracic prenatal MRI [1, 2], but other anomalies of the diaphragm are also detected in utero. Congenital diaphragmatic eventration results from a focal thinning of the diaphragm, secondary to a defective development of its musculature [3]. Unilateral or bilateral diaphragmatic paralysis can also be detected during pregnancy. Extralobar pulmonary sequestration is a congenital lung lesion consisting of non-functional lung tissue with separate pleural investment and systemic vascular supply. The most frequent location is the left costophrenic angle but it can be observed in the abdomen or enclosed within the diaphragm [4]. Exceptionally, primary diaphragmatic tumors and infiltration of the diaphragm by tumors originating from an adjacent organ have been observed in utero [5-7].

Extensive diaphragmatic hernias end eventrations are associated with high rates of neonatal morbidity and mortality because there is almost always associated impaired development of the fetal lungs and there are frequently other associated anomalies. Prenatal imaging helps to identify these anomalies, which are present in approximately $40 \%$ of fetuses with diaphragmatic pathology [8] and contribute to their final prognosis. Moreover, multiple syndromes include diaphragmatic defects as part of their pathology (Tables 1 and 2) [9-11]. 
Table 1 The most important syndromes presenting with congenital diaphragmatic pathology [9]

\begin{tabular}{|c|c|}
\hline Beckwith-Wiedemann & $\begin{array}{l}\text { Craniofacial dysmorphism, omphalocele, umbilical hernia or diastasis recti, gigantism or hemihypertrophia, } \\
\text { visceromegaly, embryonal tumors, posterior eventration of the diaphragm }\end{array}$ \\
\hline Berkenstadt & Congenital diaphragmatic hernia, pulmonary agenesis, microphthalmia \\
\hline Bieber & Congenital diaphragmatic hernia, pulmonary hypoplasia/agenesis and hydrocephalus in siblings \\
\hline Brachmann-de Lange & $\begin{array}{l}\text { Micro-brachycephaly; limb anomalies; hirsutism; cryptorchidism; marked mental, motor and social } \\
\text { retardation; congenital diaphragmatic hernia }\end{array}$ \\
\hline Cantrell pentalogy & Diaphragmatic defect, omphalocele, sternal cleft, ectopia cordis and congenital heart disease \\
\hline Dennis-Drash & $\begin{array}{l}\text { Gonadal dysgenesis, progressive glomerular disease, nephroblastoma, chromosomal anomalies, congenital } \\
\text { diaphragmatic hernia }\end{array}$ \\
\hline Donnai-Barrow & Congenital diaphragmatic hernia, deafness, absent corpus callosum, hearing loss, hypertelorism and myopia \\
\hline Downing & Congenital diaphragmatic hernia and tracheal agenesis \\
\hline Ehlers-Danlos & $\begin{array}{l}\text { Joint hypersensibility, abnormal stretchability of the skin, fragility of blood vessels, congenital diaphragmatic } \\
\text { hernia }\end{array}$ \\
\hline Fryns & $\begin{array}{l}\text { Diaphragmatic defects, lung hypoplasia, cardiovascular anomalies, genitourinary and digestive system } \\
\text { anomalies, cerebral anomalies, cleft/lift palate, hypoplastic fingers or toenails, coarse facial features }\end{array}$ \\
\hline Gershoni-Baruch & Congenital diaphragmatic hernia, omphalocele, radial ray defects and hepatic cysts \\
\hline Lurie & Congenital diaphragmatic hernia, agenesis of corpus callosum, hydrocephaly and hydrops fetalis \\
\hline Maaswinkel-Mooij & $\begin{array}{l}\text { Congenital diaphragmatic hernia, pseudohermaphroditism, hypoplastic left heart, lung aplasia, horseshoe } \\
\text { kidney }\end{array}$ \\
\hline Mathieu & Congenital diaphragmatic hernia, fused vertebrae and unusual facies \\
\hline Oner & Diaphragm agenesis, radial aplasia, preauricular tags \\
\hline PAGOD & Acronym of Pulmonary tract or artery hypoplasia, AGonadism, Omphalocele and Diaphragmatic defect \\
\hline Pallister-Killian & $\begin{array}{l}\text { Tetrasomy } 12 p \text {, craniofacial dysmorphism, mental and motor retardation, congenital diaphragmatic hernia, } \\
\text { limb anomalies }\end{array}$ \\
\hline Personage-Turner & Bilateral diaphragmatic paralysis/paradoxical motion \\
\hline Toriello & Diaphragmatic defects, sex reversal, cardiac and pulmonary defects \\
\hline Werdnig-Hoffmann & Hypotonia, expressionless face, weakness, diminished reflexes, diaphragmatic paralysis \\
\hline
\end{tabular}

Prenatal imaging methods also enable quantitative measurements of the size and volume of the lungs and evaluation of the lung vasculature. All these data help the medical team provide the best information for families and the predictions about both the immediate neonatal outcome and the risks of sequellae. Finally, they help in decisions relating to pregnancy management, optimal delivery timing and type, and immediate therapy after birth.

We review congenital pathologies of the diaphragm and analyze their embryological causes. We also describe the prenatal imaging findings of a wide spectrum of pathologies and discuss their differential diagnoses, with an emphasis on MRI.
Table 2 Congenital malformations most commonly associated with congenital diaphragmatic hernia and congenital diaphragmatic eventration [9-11]

\begin{tabular}{lll}
\hline Associated anomalies & $\begin{array}{c}\text { Estimated } \\
\text { frequency }\end{array}$ & \\
\hline Cardiovascular & $10-35 \%$ & Tetralogy of Fallot, VSD, ASD, coarctation \\
Gastrointestinal & $10 \%$ & Esophageal atresia, tracheoesophageal fistula, bowel atresia \\
Limb anomalies & $10 \%$ & $\begin{array}{l}\text { Polydactyly, syndactyly, reduction defects } \\
\text { Urogenital }\end{array}$ \\
Chromosomal & $10 \%$ & $\begin{array}{c}\text { Horseshoe kidney, crossed-fused ectopia, lower urinary tract } \\
\text { dysfunction, cryptorchidism }\end{array}$ \\
CNS & $10 \%$ & $\begin{array}{c}\text { Trisomies } 13,18,21 \text { and } 22, \text { tetrasomies } 12 \mathrm{p}, 8 \mathrm{q} 22 \\
\text { translocation, } 18 \text { p syndrome, deletion } 3\end{array}$ \\
Pulmonary & $5-10 \%$ & $\begin{array}{c}\text { Spina bifida, holoprosencephaly, neural tube defects, } \\
\text { hydrocephalus. }\end{array}$ \\
& $<5 \%$ & $\begin{array}{c}\text { Extralobar sequestration, pleural effusion, pulmonary } \\
\text { hypertension. }\end{array}$ \\
\hline
\end{tabular}

$A S D$ atrial septal defect, $C N S$ central nervous system, $V S D$ ventricular septal defect 
Finally, we describe the most commonly used measurements and indexes for evaluating fetal lung hypoplasia and pulmonary hypertension and discuss the limits of prenatal imaging for predicting the postnatal outcome.

\section{Embryology of the diaphragm}

An appropriate knowledge of embryology is crucial for understanding the congenital pathology of the diaphragm and its consequences on the lung development. However, the embryology of the diaphragm still remains controversial and poorly understood.

Diaphragmatic defects have traditionally been considered to result from the failure of the different parts of the diaphragm to fuse properly. The diaphragm forms between the 4th and 12th weeks of gestation from four components: the transverse septum, the pleuro-peritoneal membranes, the dorsal mesentery of the esophagus, and the lateral body walls (Fig. 1) [12, 13]. At the 4th week, the embryo presents a single, horseshoe-shaped body cavity. By the 6th week, the anteriorly located transverse septum becomes the central tendon of the diaphragm. The septum grows dorsally and begins to form a semicircular shelf that separates the heart from the liver. Simultaneously, the posterolateral pleuro-peritoneal membranes extend progressively ventrally and fuse with the transverse septum and the dorsal mesentery of the esophagus. At the 7th week, the transverse septum fuses with the muscular body walls laterally, completing the membranous diaphragm and finishing division between thorax and abdomen [12-14]. Impairments occurring at this time would be at the origin of the congenital diaphragmatic hernia (Fig. 1).

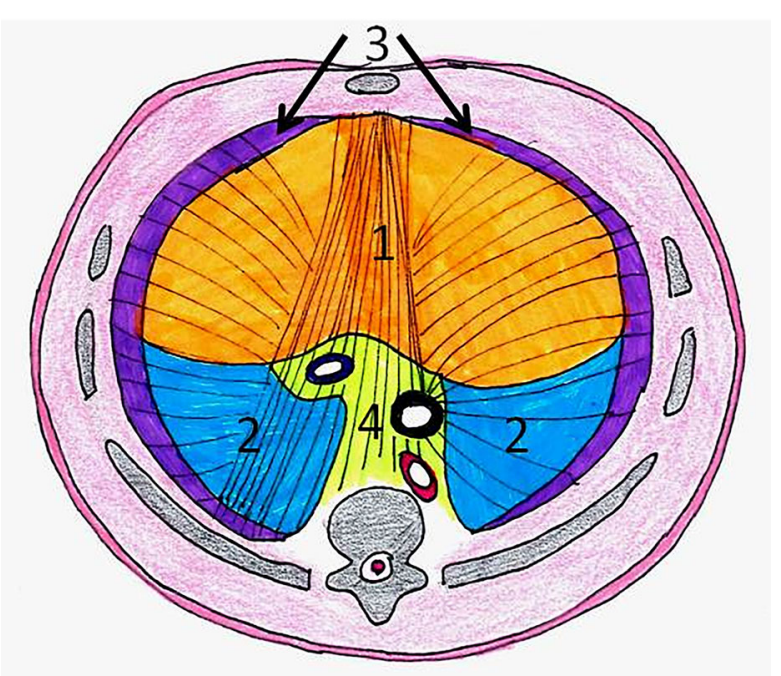

Fig. 1 Embryological origin of the diaphragm: (1) horizontal septum transversum (orange), (2) pleuroperitoneal membranes (blue), (3) body wall muscular fibers (violet), (4) dorsal mesentery of the esophagus (green)
At $8-10$ weeks of gestation, muscular fibers arising from the cervical myotomes grow in the lateral body wall and incorporate the intercostal muscles within the membranous diaphragm $[12,14,15]$. The internal layer of the body wall then forms the muscle of the peripheral diaphragm. Postero-lateral remnants of the pleuro-peritoneal membranes form a fibrous trigone in each hemidiaphragm that constitute most of its muscular part [16-18], whereas the median part of the muscular diaphragm forms from the dorsal mesentery of the esophagus. Impairments in this period would cause a complete or partial absence of the muscular diaphragm as observed in congenital diaphragmatic eventration.

The development of the fetal lungs is synchronous with that of the diaphragm, which explains the commonly associated pulmonary hypoplasia observed in fetuses with diaphragmatic pathology. The lungs begin their development as a ventral outpouching of the primitive foregut at the 3 rd week of gestation. They progressively increase in size between the 9th and 12th weeks, while the pleural cavities extend into the lateral body walls, forming the costo-diaphragmatic recesses and helping to establish the final dome-shaped configuration of the diaphragm [12]. Lung sequestrations developed at this time can end up embedded into the leaflets of the diaphragm.

In 1984 Iritani [19] described the posthepatic mesenchymal plate, a structure that appears dorsal to the liver, ventral to the pleuroperitoneal canal and caudal to the transverse septum at early fetal life. He suggested that anomalous development of the posthepatic mesenchymal plate would lead to an impaired fusion between the plate itself and the pleuroperitoneal folds, causing a congenital diaphragmatic defect. Based on this theory, Mayer et al. [20] showed that in normal rats the ingrowth of the posthepatic mesenchymal plate and the approximation of the adjacent organs leads to progressive closure of the pleuroperitoneal canal, completing the formation of the diaphragm at day 16; in nitrogen-exposed rats, however, the posthepatic mesenchymal plate appears smaller and malformed, causing an abnormally high position of the ipsilateral diaphragm and leaving parts of the liver undercovered. The remaining opened pleuroperitoneal canal would incorporate the defect, which would cause the diaphragmatic hernia; the intrathoracic space would therefore be reduced and the lung development secondarily impaired.

\section{Abnormalities of the diaphragm}

\section{Congenital diaphragmatic hernia and eventration}

Congenital diaphragmatic hernia is by far the most common prenatally detected thoracic pathology and the most common diaphragmatic anomaly reported in the literature. It occurs in $<1$ to $<5$ in 10,000 live births [1,2] but prevalence and incidence vary depending on whether stillborn babies are included 
in estimates $[10,21]$. The number of fetuses with congenital diaphragmatic hernia in early pregnancy loss is not really known, and in many cases of prenatal diagnosis pregnancy is terminated $[8,10]$. Most hernias are first suspected at US pregnancy screening exams at the 18th to 22 nd weeks of gestation, but they have been identified as early as the first trimester of pregnancy [22]. They are associated with high rates of morbidity and mortality, mainly from pulmonary hypoplasia caused by the chronic compression of the developing lungs by the herniated abdominal organs. Mortality rates vary based on differences in reporting procedures, but most series show $30-40 \%$ mortality in isolated diaphragmatic hernias, and higher rates in the presence of associated anomalies [23] (Table 1). Other poor-outcome prognostic criteria include thoracic liver herniation, non-visualization of the lung ipsilateral to the hernia and imaging findings suggesting severe lung hypoplasia [24-26].

Congenital diaphragmatic hernias have traditionally been classified as posterolateral or Bochdalek, anterior or Morgagni, and central or hiatal hernia (Fig. 2). A new classification has been recently proposed by the Texas Children's Fetal Center; it differentiates intrapleural from mediastinal hernias, but it is not extensively used [10]. The Bochdalek hernia — intrapleural according to the Texas Children's classification - represents $70-90 \%$ of all diaphragmatic hernias in live births. It is on the left in $80-90 \%$ of cases $[11,13]$. It results from a defect in the diaphragm caused by a malformation of the pleuro-peritoneal folds or from a failure of fusion between the pleuro-peritoneal folds and the transverse septum with the intercostal muscles $[10,11,15]$. The anterior Morgagni hernia represents $12-15 \%$ of diaphragmatic defects in infancy and is caused by a defect in the fusion of the transverse septum to the lateral body wall, with the herniated organs passing between the sternal and the costal heads of the diaphragm (Fig. 2) $[8,10,11]$. Central hernias represent only $2-5 \%$ of all congenital hernias in infants, and in this type the abdominal organs pass

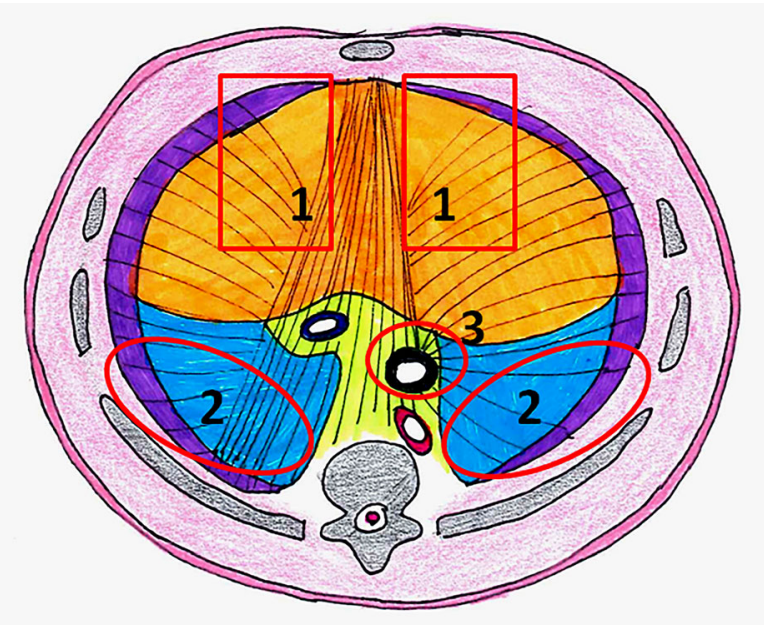

Fig. 2 Anatomical location of the most important diaphragmatic hernias: (1) anterior Morgagni hernia, (2) posterior Bochdalek hernia, (3) central hiatal hernia through the esophageal hiatus [21] (Fig. 2) [10, 11]. Both Morgagni and central hernias are considered mediastinal, according to the Texas Children's classification.

As mentioned, the real incidence of congenital diaphragmatic hernia is difficult to establish because the published data refer almost exclusively to live births. Left hernias account for about $85 \%$ of all congenital diaphragmatic hernias in live births $[1,8,10]$. In general, they are easier to identify at imaging and have a better prognosis than right hernias. The most frequently detected left hernia is the Bochdalek hernia, which is often associated with a displacement of the stomach, the small bowel or the spleen into the thorax (Fig. 3). Thoracic herniation of the left hepatic lobe is observed in extensive defects, usually associated with a posteriorly displaced herniated stomach. In these cases, a distortion of the hepatic or the umbilical veins in the herniated liver might be observed at imaging. Extensive hernias cause a right cardio-mediastinal shift and severe bilateral lung hypoplasia [10].

Right-side hernias represent $12-15 \%$ of all congenital diaphragmatic defects in live births $[8,10]$. Their prenatal detection rate is lower than that of left hernias because the liver and the right lung parenchyma present a similar echogenicity and are difficult to differentiate from each other at US screening exams. In right hernias the liver is almost invariably partly intrathoracically located and an abnormal position of the gallbladder and of the hepatic vasculature might be observed at imaging. Variable amounts of bowel displaced into the thorax are often observed. The stomach usually remains in the abdomen, although it often shows a distortion of its normal position. Once more, extensive hernias usually cause a left posterior cardiomediastinal shift and a severe unilateral or bilateral lung hyploplasia (Fig. 4).

Central hiatal hernias represent only $2-5 \%$ of all congenital diaphragmatic hernias [23]. The stomach is the most often herniated organ, passing through the esophageal hiatus (Fig. 5), whereas the liver usually remains in the abdomen. This type of hernia rarely produces significant pulmonary hypoplasia and is rarely diagnosed in utero.

Congenital diaphragmatic eventration is uncommon, accounting for about $5 \%$ of all diaphragmatic defects [3]. It is caused by a focal defective musculature of the diaphragm, with absence or impaired development of the diaphragmatic muscle fibers in the involved region $[12,15]$. The absence of the muscle leads to a focal thinning of the diaphragm [11], which forms a pocket-like outpouching, allowing the displacement of the abdominal organs into the thorax. The most often observed location is the antero-medial portion of the right hemidiaphragm, usually associated with a partial elevation of the right liver lobe [18]. However, a whole hemidiaphragm or even both hemidiaphragms may be involved [12, 14] (Figs. 6 and 7).

A partial elevation of a hemidiaphragm with a normal position of the uninvolved part should suggest the diagnosis, but the thinned membrane is not always detected. Indeed, 


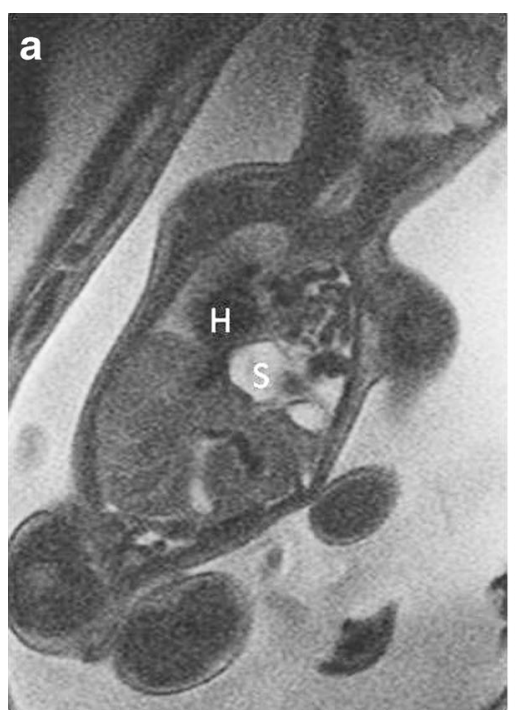

Fig. 3 Left congenital diaphragmatic hernia in a male fetus. a, b Coronal T2-W MR images obtained at 31 weeks of gestation show the mediastinal shift, with the heart $(H)$ located in the right hemithorax. The stomach $(S)$, most of the small bowel and part of the colon are intrathoracic. The liver is
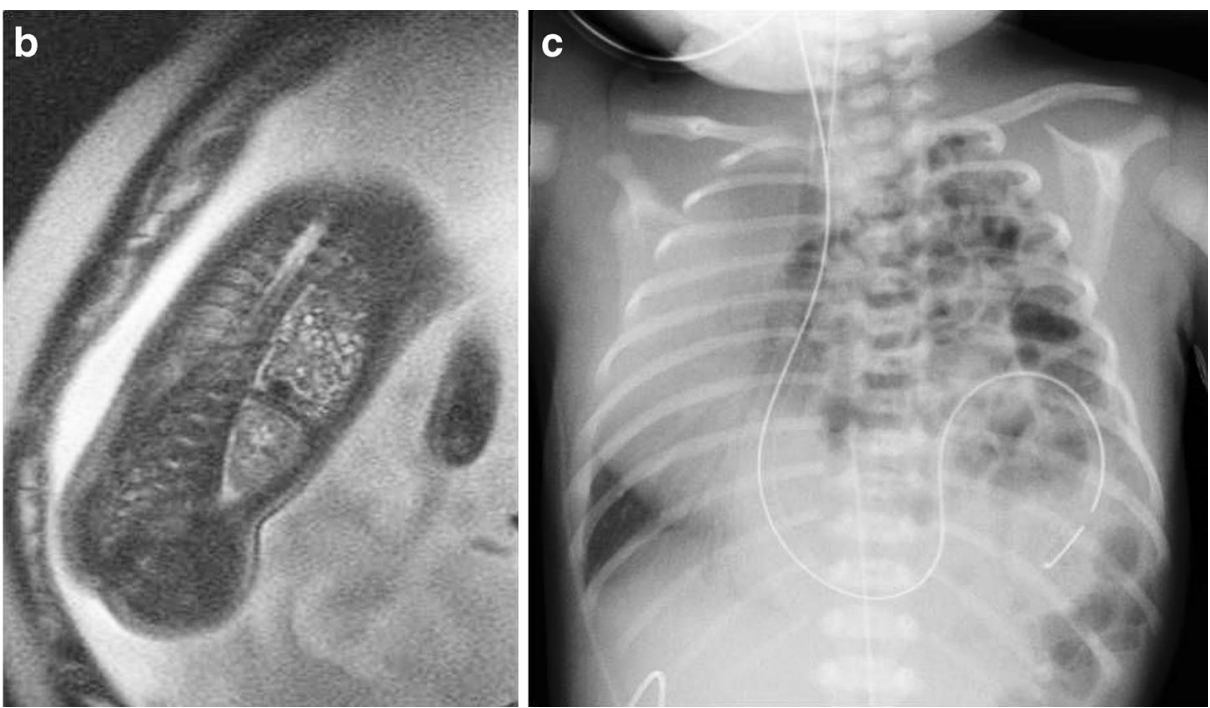

not herniated and the left lung is not identified. c Chest radiograph obtained at day 1 after birth confirms the left intrathoracic-located airfilled intestine causing mediastinal shift. Note the abnormal course of the gastric tube
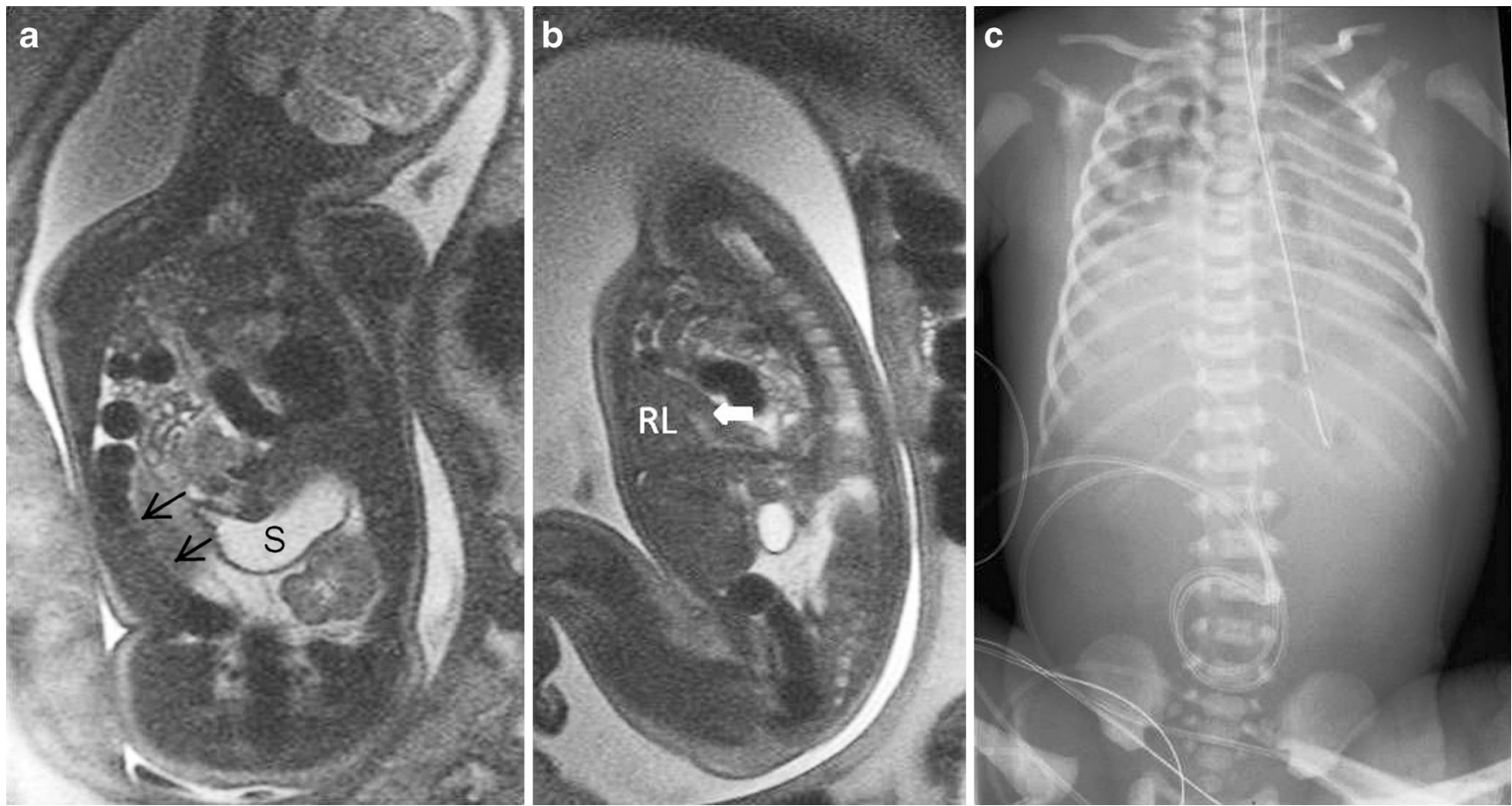

Fig. 4 Right congenital diaphragmatic hernia in a male fetus. a, b Coronal (a) and right sagittal (b) T2-W MR images obtained at 31 weeks of gestation demonstrate the extensive right diaphragmatic hernia. A significant amount of the small bowel and colon, and the right hepatic lobe (RL, arrow in b) are intrathoracically located, whereas the stomach $(S)$ remains intra-abdominal. The meconium-filled colon (arrows in a) is clearly identifiable, appearing hypointense on T2-
W images. There is significant mediastinal shift and severe bilateral lung hypoplasia. c Anteroposterior chest and abdomen radiograph obtained a few minutes after birth shows the right intrathoracically located air-filled intestines and confirms the normal position of the stomach. The boy died at 2 days of age from severe respiratory insufficiency and pulmonary hypertension 
Fig. 5 Central hiatal hernia in a baby girl. a Anteroposterior chest radiograph in a 4-day-old girl who presented with alimentary difficulties and vomiting. The gastric tube shows the position of the stomach, herniated into the central thorax through the esophageal hiatus. b, $\mathbf{c}$ Anteroposterior (b) and lateral (c) upper gastrointestinal opacification images demonstrate a gastric volvulus with downward-pointing pylorus and duodenum (arrows). The esophagus is short, and significant gastro-esophageal reflux is observed (b). Pathology had not been detected in utero
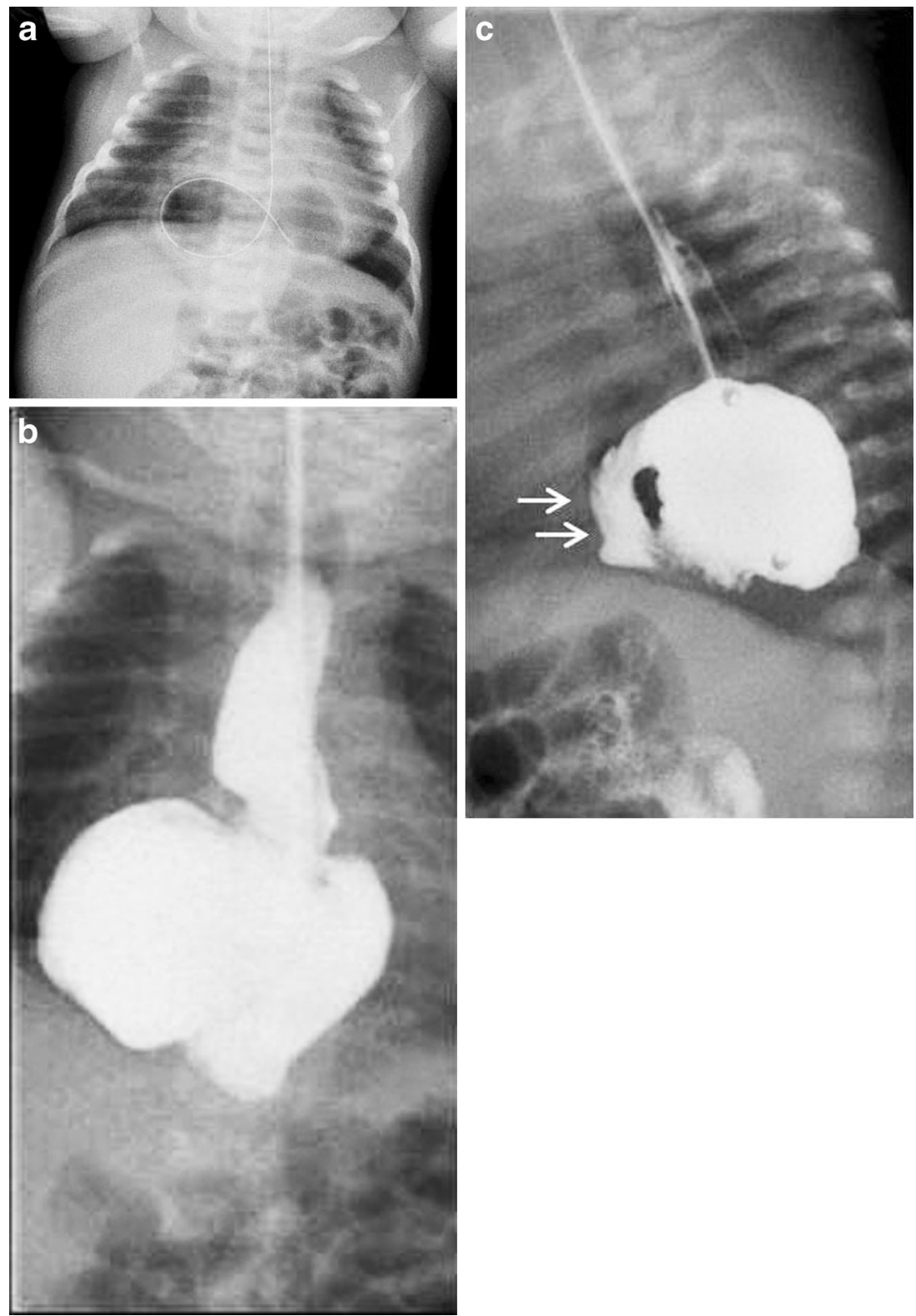

extensive eventrations are extremely difficult to differentiate from congenital hernias at prenatal imaging [13, 15]. Right eventrations can produce non-immune hydrops fetalis, probably from the compression of the superior and inferior vena cava, with chronic impairment of the venous return and secondary low-output cardiac failure [14] (Fig. 7). Congenital eventrations have the same consequences on the development of the fetal lungs as congenital hernias, but in general they present a better prognosis.

\section{Prenatal diagnosis of congenital diaphragmatic defects}

A congenital diaphragmatic defect is most often first detected with pregnancy US screening exams performed between the 18th and 22nd weeks of pregnancy. The normal diaphragm is observed as a fine, regular and hypoechogenic dome-shaped structure separating the thorax from the abdomen. The sensitivity for prenatal detection of diaphragmatic pathology at US depends mainly on the experience of the examiner but also on the gestational age, the side of the lesion and the severity of the pathology, the presence or absence of displacement of the abdominal organs into the thorax and the presence or absence of associated anomalies (Table 1). The prenatal detection rate of right defects is lower than that of the left because the liver and the lung parenchyma present a similar echogenicity at US exams, whereas the fluid-filled herniated stomach, small bowel and colon in left hernias are easier to distinguish. As already described, extensive hernias cause cardio-mediastinal shift and bilateral lung hypoplasia [10]. 
Fig. 6 Bilateral congenital diaphragmatic eventration in a female fetus. a-c Coronal (a) and sagittal (b, c) T2-W MR images obtained at 29 weeks of gestation identify only the ventral diaphragm (arrow in b). The fetal lungs are not seen and both liver and intestines are partly located in the thorax. Note the significant amount of fluid in either the thorax or abdomen. Suggested prenatal diagnosis was bilateral congenital diaphragmatic hernia. Pregnancy was terminated because of the severe lung hypoplasia and the development of hydrops. d Macroscopic photograph of the fetal specimen reveals an intact but thinned-out diaphragm without diaphragmatic muscle fibers (arrow), establishing the diagnosis of bilateral eventration. Note that the diaphragm is inverted compared to its usual presentation
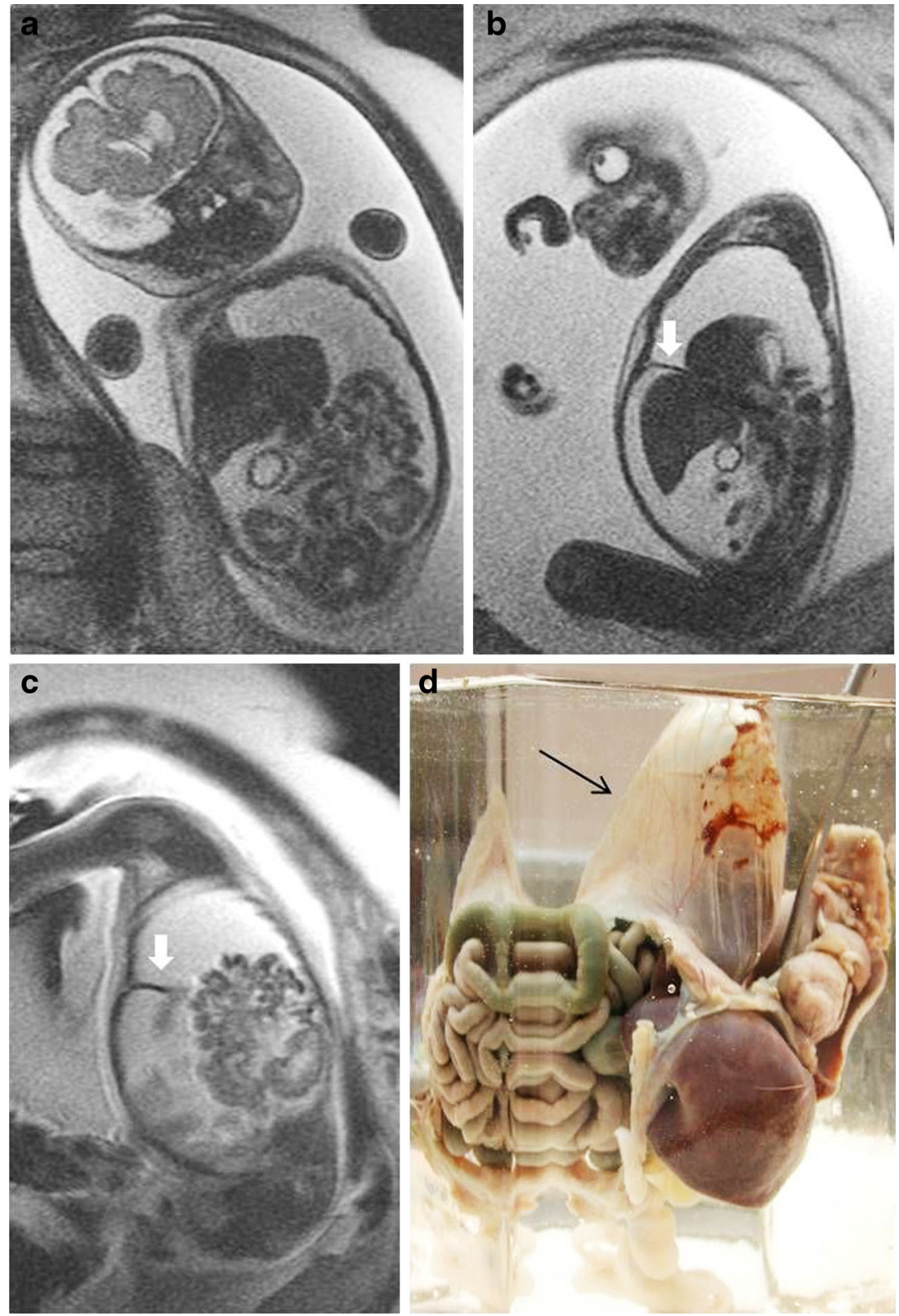

US exams also provide a dynamic evaluation of the diaphragm and allow comparison of the hemidiaphragms during fetal breathing when performed in advanced pregnancy [22]. In diaphragmatic hernias and eventrations, paradoxical movement of the abdominal contents during fetal breathing has been occasionally reported. It consists of a downward movement of the abdominal organs on the normal side and a rising upward movement of the herniated abdominal contents into the chest during fetal inspiration. Additional color Doppler US exams should be performed in case of suspected diaphragmatic pathology and can identify the abnormal position of the intrahepatic vessels in thoracic herniated liver [22, 27].
If pathology of the diaphragm is suspected at US, MRI is often performed. MRI allows for a better spatial resolution and tissue characterization than US. Moreover, MRI's large field of view and multiplanar possibilities provide complete and detailed documentation of the fetal anatomy, even at lateterm pregnancy and independently of the fetus position. Prenatal MRI might help to clarify the liver position because lung and liver parenchyma have clearly different signal intensities and can be easily distinguished from each other. In herniated liver, the hepatic vessels extending above the level of the diaphragm might be observed as linear structures, appearing as high signal intensity on $\mathrm{T} 2-\mathrm{W}$ images. The digestive organs can also be clearly identified because of the different signal intensities of the fluids filling the organs: the amniotic fluid 
Fig. 7 Bilateral congenital diaphragmatic eventration in a male fetus. a Coronal T2-W MR image obtained at 33 weeks of gestation shows the high position of both hemidiaphragms (arrows) and demonstrates severe bilateral lung hypoplasia. b, c Left (b) and right (c) sagittal T2-W MR images show the integrity of both hemidiaphragms. d

Anteroposterior chest and abdomen radiograph obtained right after birth confirms the high position of the hemidiaphragms and the reduced bilateral lung volume. The boy died shortly after birth because of respiratory insufficiency. $H$ heart, $R L$ right lung
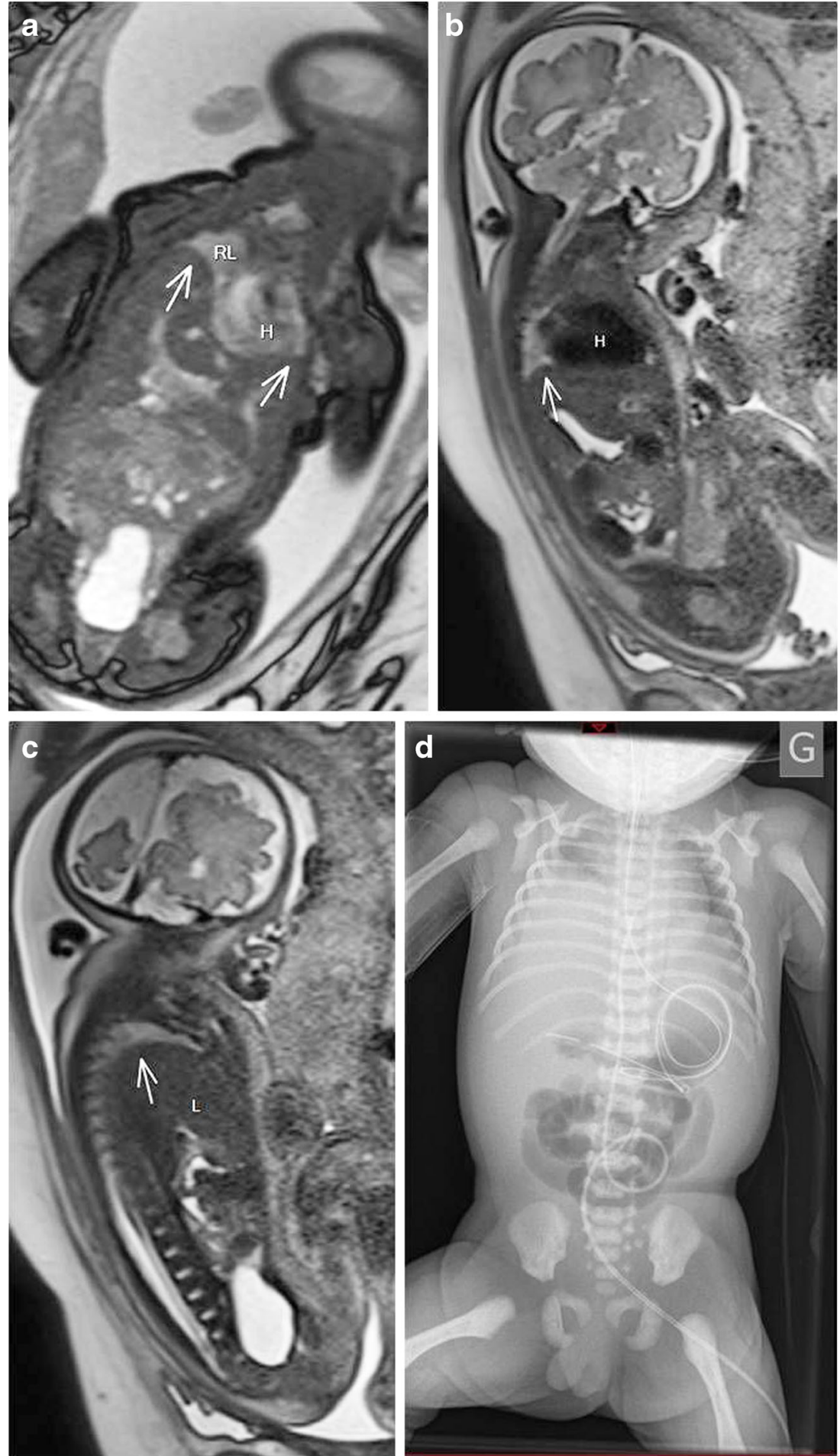

observed in the stomach and the proximal bowel is hyperintense on $\mathrm{T} 2-\mathrm{W}$ and hypointense on $\mathrm{T} 1-\mathrm{W}$ images, whereas the meconium present in the distal small bowel, colon and rectum is hypointense on $\mathrm{T} 2-\mathrm{W}$ and hyperintense on T1-W images. The standard protocol for MR exams at our institution includes a $\mathrm{T} 1-\mathrm{W}$ volumetric interpolated breath-hold examination with gradient-echo sequence (repetition time [TR]/echo time [TE] of 3.69/ $1.6 \mathrm{~ms}$, matrix $192 \times 256$ ); a T2-W half-Fourier singleshot turbo spin-echo sequence (TR/TE 999/88 ms, matrix $307 \times 512$ ); and a $\mathrm{T} 2-\mathrm{W}$ steady-state free precession gradient-echo sequence (TR/TE 6.44/3.22 ms, matrix $230 \times 512$ ). All sequences are performed in the three fetal spatial planes. 


\section{Prediction of postnatal outcome of congenital diaphragmatic hernias and eventrations in utero}

In view of the high mortality associated with diaphragmatic pathology, different approaches based on prenatal imaging have been used to predict the individual postnatal outcome. Predictors can be divided into two main groups: those that rely entirely on measurements of the lung size or volume and those that evaluate the pulmonary vasculature. The most important prenatal predictors are described in Table 3.

At US the most commonly used method for evaluating the severity of lung hypoplasia is the lung-to-head ratio, which is the ratio between the lung area contralateral to the hernia obtained at the level of a four-chamber view of the fetal heart in cross-sectional images and the head circumference of the fetus $[27,28]$. This value has been shown to be a prognostic factor in fetuses with diaphragmatic hernia: a lung-to-head ratio of $>1.6$ is associated with a $>83 \%$ survival rate, $1-1.6$ with a $66 \%$ survival rate and $<1$ with a $16 \%$ survival rate [29]. The observed-to-expected lung-to-head ratio results from comparing the obtained measures in patients with congenital diaphragmatic hernia with the expected mean values in normal fetuses at the same time of gestation, expressed as a percentage [30].

Volumetric lung measurements can be done by either 3-D US or MRI. Echographic pulmonary volumetries are usually performed in the second trimester of gestation and have not shown significant differences from lung-to-head ratio in predicting survival [31]. Volumetric MRI measurements are part of routine prenatal thoracic MRI studies. Axial T2-W sequences covering the fetal thorax in a single acquisition are used for calculation. The area of lung tissue visible on each section is outlined by using free-hand drawing sampling in each slide of the selected sequence, summed separately for each lung field and multiplied by the section thickness to obtain a volume [32]. Measures of the right and left lung volumes are added to obtain the observed total fetal lung volume and are then expressed as a percentage of the mean expected normal values for the time of gestation $[8,33,34]$. Observed-to-expected total fetal lung volume measurements $<15-25 \%$ present a significantly higher mortality rate, higher rates of extracorporeal membrane oxygenation treatment and higher risk of chronic respiratory problems compared to fetuses with higher percentages [11, 33, 34]. Finally, the exact amount of liver herniation into the thorax can be measured as the herniated liver-to-thoracic volume ratio. The volume of the thorax and that of the herniated liver are measured at MRI using the xyphoid process and the thoracic apex in transverse images as landmarks, and their ratio is calculated. High volumes of herniated liver represent a poor prognostic parameter [30, 35-37].

Concerning the fetal lung vasculature, different methods for its prenatal assessment have been described. The pulsatility index evaluates changes in the fetal pulmonary arteries following the administration of maternal oxygen. The McGoon index (MGI) at US and the modified McGoon index at MRI are calculated as the sum of the diameters of the right and left pulmonary arteries obtained at the bifurcation in systole in US studies and in the axial plane at MRI and divided by the diameter of the aorta, measured at the level of the diaphragm [38]. Studies have shown that these methods are useful not only for predicting survival but also the severity of postnatal pulmonary arterial hypertension [37, 38]. Finally, the prenatal pulmonary hypertension index is calculated as the left pulmonary artery diameter measured in axial MR images, divided by the length of the vermis of the cerebellum
Table 3 The most commonly used predictors for lung hypoplasia and pulmonary hypertension based on prenatal imaging findings

\begin{tabular}{|c|c|c|}
\hline & $\begin{array}{l}\text { Imaging } \\
\text { method }\end{array}$ & Description \\
\hline Lung-to-head ratio (LHR) & US & $\begin{array}{l}\text { Lung area contralateral to the hernia } \\
\text { Head circumference of the fetus }\end{array}$ \\
\hline Observed-to-expected LHR & US & $\begin{array}{l}\text { LHR observed } \times 100 \\
\text { LHR expected }\end{array}$ \\
\hline Liver-to-thoracic volume ratio & MRI & $\begin{array}{l}\text { Herniated liver volume } \times 100 \\
\text { Thoracic volume }\end{array}$ \\
\hline $\begin{array}{l}\text { Observed-to-expected total fetal } \\
\text { lung volume (TFLV) }\end{array}$ & MRI & $\begin{array}{l}\text { TFLV observed (right } \pm \text { left lung volume) } \times 100 \\
\text { TFLV expected (right }+ \text { left lung volume) }\end{array}$ \\
\hline McGoon index & US & $\begin{array}{l}\text { Right } \pm \text { left pulmonary artery diameter (bifurcation) } \\
\text { Thoracic aorta diameter (diaphragm level) }\end{array}$ \\
\hline Modified McGoon index & MRI & $\begin{array}{l}\text { Right } \pm \text { left pulmonary artery diameter (axial plane) } \\
\text { Thoracic aorta diameter (diaphragm level) }\end{array}$ \\
\hline Pulmonary hypertension index & MRI & $\begin{array}{l}\text { Left pulmonary artery diameter (axial plan) } \times 10 \\
\text { Length of the vermis (midline sagittal) }\end{array}$ \\
\hline
\end{tabular}


in a midline sagittal plane and multiplied by 10 . This index seems to also be useful for predicting the severity of postnatal pulmonary hypertension [38].

However, in utero imaging does not always detect congenital diaphragmatic defects. The mean reported rates for the detection of hernias and eventrations at prenatal US are $>70 \%$ but vary from $18 \%$ to $87 \%[16,39,40]$. Obviously the absence of prenatal diagnosis prevents the medical team from preparing for the immediate postnatal care, but it has been suggested that most undetected cases correspond to smaller, isolated hernias without poor prognostic parameters during pregnancy.

After birth, pulmonary hypoplasia can cause respiratory insufficiency and immediate death. At histology, hypoplastic lungs present impaired, incomplete divisions of the bronchial tree, a reduced alveoli number and a decreased vascular bed compared to the normal lungs [41]. The predictions of neonatal outcome are mainly based on the volumetric measurements of the fetal lung at a specific gestational period, but a recently published study has shown that the severity of pulmonary hypoplasia is dynamic and can worsen in the third trimester, suggesting the utility of performing serial MRI-based volumetric measures [42]. Moreover, in extensive hernias volumetric measurements are often limited to the lung contralateral to the hernia because the ipsilateral lung is often highly compressed and not seen. It has been reported that the lung volume contralateral to the hernia is underestimated by $25 \%$ and the ipsilateral lung is not visualized for measurements in nearly $45 \%$ of evaluations at 3-D US [27]. Hypoplasia is more marked in the lung ipsilateral to the hernia than in the contralateral one, but in operated patients the ipsilateral lung would expand and contribute to ventilation. However, this functional capacity remains impossible to predict in utero.

The severity of hypoplasia does not always regress later in life. Lung volumes increase significantly with time, but longterm follow-up studies in children with surgical repair of congenital diaphragmatic hernias have shown persistent reduced lung perfusion in the lung ipsilateral to the hernia compared to the contralateral lung [43]. Recently, Balassy et al. [44] assessed development of both lungs in patients with isolated congenital diaphragmatic hernia by using lung/liver signal intensity ratios on $\mathrm{T} 1-$ and $\mathrm{T} 2-\mathrm{W}$ images. They found that lung/liver signal intensity ratios were significantly higher in both lungs on T1-W and significantly lower on T2-W images compared with normal lungs and concluded that although these changes seem to reflect developmental impairment in both lungs, they provide no additional information in predicting final outcome.

Measurements of lung size and volume are useful to predict the degree of pulmonary hypoplasia but they do not seem to correlate with the severity of postnatal pulmonary arterial hypertension, which is at the origin of most cases of chronic respiratory disability. Recent preliminary studies have shown that both the prenatal calculated modified McGoon index and the pulmonary hypertension index seem to predict the postnatal severity of lung hypertension [45]. However the individual postnatal outcome is multifactorial and depends not only on the degree of pulmonary hypoplasia and hypertension but also on the presence or absence of a syndrome or of associated anomalies, the gestational age and the weight at birth and the individual response to therapy in the first days of life, among others. Therefore prenatal predictions remain extremely difficult.

\section{Overview of therapies}

Different pre- and postnatal therapies have been evaluated in patients with diaphragmatic defects. A detailed description of these therapies is outside the scope of this article, but we will briefly mention the most relevant. Fetal surgery with temporary fetal endoscopic tracheal occlusion, also known as FETO, is performed in selected cases, mainly in fetuses with poor prognostic parameters and considered otherwise unviable [1, $46,47]$. Fetuses requiring prenatal intervention are included in a randomized trial in some European countries. Preliminary results are promising, with survivals approaching $50 \%$. These patients have a lower alveolar-arterial oxygen gradient and a greater respiratory compliance than controls [30]. Occasionally ex utero intrapartum treatment, also known as EXIT, is required to reverse the occlusion before delivery [48, 49]. In this procedure, the fetus is partly removed through a hysterectomy in order to establish a safe airway via intubation or tracheotomy while maintaining the placental circulation. However, FETO therapy remains limited to a few highly specialized centers [46, 47] because difficulties with removing the balloon at delivery have led to a centralization of these patients.

After birth, extracorporeal membrane oxygenation (ECMO) can be a useful adjunct in extensive diaphragmatic defects. It consists of the cannulation of both the right carotid artery and the right jugular vein and their connection to a circuit with a membrane gas exchange chamber. It allows both oxygenation and $\mathrm{CO}_{2}$ disposal without involving the lung [50], but it has risks. The limitations of the technique (required weight $>2,000 \mathrm{~g}$, need for heparinization) and the weak evidence of its real benefits have cast doubts about its efficacy and reduced the proportion of patients treated with this method $[1,51]$.

Finally, postnatal medical therapy is complex and includes immediate intubation, small-volume, high-frequency oscillatory ventilation [52], and intensive medication for treatment of pulmonary hypertension [53]. This therapy must be maintained for an indeterminate period of time before the child is stable for surgical correction of the hernia, which is the main objective for these infants. 


\section{Congenital diaphragmatic paralysis}

Diaphragmatic paralysis is difficult to recognize in utero and in most cases can only be definitively confirmed after birth. The diaphragm is mainly innervated by the phrenic nerves, with additional involvement of the lower intercostal nerves. The paralysis can be unilateral or bilateral. Bilateral dysfunction is often associated with pathology of the central nervous system, whereas unilateral dysfunction is usually observed in children with cardiac pathology [13]. At prenatal imaging an asymmetry in the position of the hemidiaphragms in a fetus with detected cardiac pathology should suggest the diagnosis (Fig. 8).

Unilateral paralysis is almost impossible to differentiate from extensive congenital diaphragmatic eventration at prenatal exams, but elevation of the diaphragm by paralysis usually involves the entire hemidiaphragm, whereas in most cases of congenital diaphragmatic eventration only a portion of a hemidiaphragm is elevated [12-15]. Coronal US and MRI images might compare the position of the hemidiaphragms and show the elevation of the involved diaphragm. US exams also facilitate the dynamic evaluation of the diaphragm during fetal breathing at late-term pregnancy, but to our knowledge prenatal paradoxical movement of the diaphragm has not been reported related to paralysis.

\section{Intradiaphragmatic extralobar pulmonary sequestrations}

Pulmonary sequestration is a congenital lung anomaly $[4,54]$ consisting of non-functional lung tissue that lacks normal communication with the tracheo-bronchial tree and presents with anomalous vascularity. It is classified as extra- and intralobar types. Intralobar lesions are located within the lung parenchyma whereas extralobar have a separate pleural covering. Both variants are supplied by the systemic arteries - the descending aorta or one of its major branches - but the venous drainage is via the pulmonary veins for the intralobar type and via the systemic veins for the extralobar.

Today extra- and intralobar sequestrations are often detected in utero (Fig. 9). The most common location of extralobar sequestration is the left costo-phrenic angle, but it might be observed in the abdomen and, exceptionally, embedded within the diaphragm $[4,6,55,56]$. This last location might be explained by the simultaneous timing of the development of the diaphragm, the pleura and the lungs during early embryonic life. A sequestration formed in this period could remain enclosed between the pleuro-peritoneal folds and the muscular diaphragm [55]. Prenatal imaging of extralobar sequestration usually reveals a well-defined, relatively homogeneous mass, hyperechoic at US and with high signal intensity on T2-W MR images related to the normal lung. The anomalous systemic vascular supply can be identified with both US Doppler and MR imaging to confirm the diagnosis. However, a diaphragmatic localization is extremely rare and is therefore usually not suspected in utero. After birth, coronal reformatted images from contrast-enhanced CT chest scans might show the split hemidiaphragm sign, which consists of the visualization of the two identifiable leaflets of the diaphragmatic muscle encasing the mass, suggesting the diaphragmatic localization [55]. However, it is usually first discovered during surgery, often requiring a double-thoracic and abdominal-surgical approach [54-56].
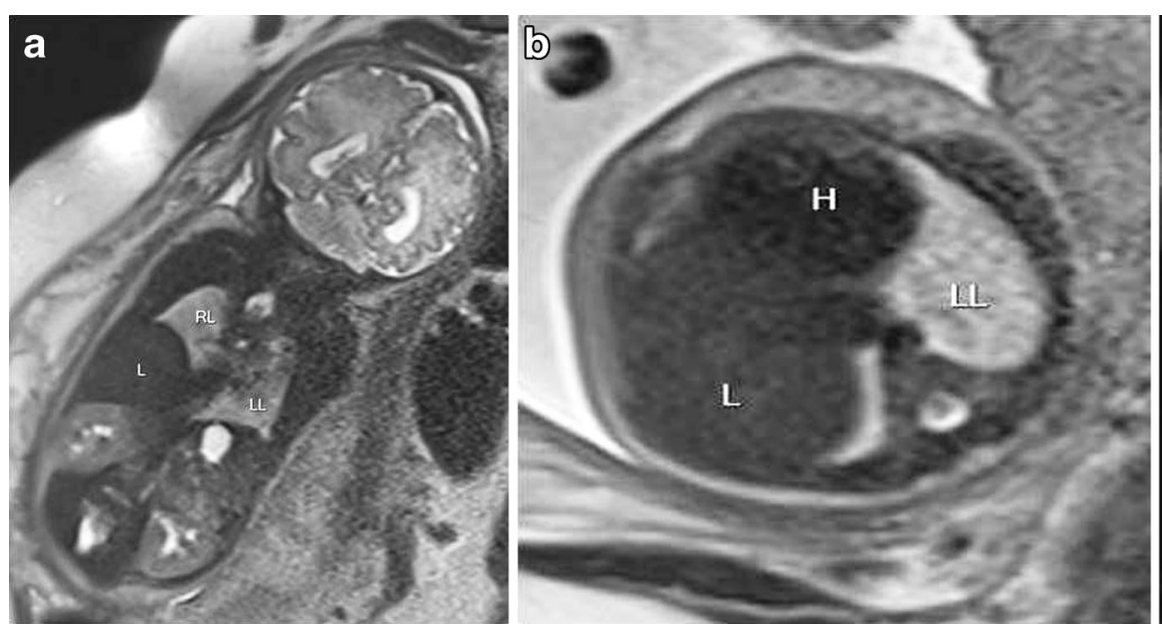

Fig. 8 Right diaphragmatic paralysis in a male fetus. a Coronal T2-W MR image obtained at 33 weeks of gestation shows the high position of the right hemidiaphragm compared to the normal left side. b Transverse T2-W image at the thorax basis shows a normal left lung $(L L)$ and a high right hepatic lobe $(L)$. There is no significant mediastinal shift. $\mathbf{c}$ Postnatal chest radiograph at 1 day old confirms the high position of the right hemidiaphragm. Sonographically there was reduced movement of the right hemidiaphragm (not shown). Karyotyping showed trisomy 13 and there were several associated anomalies, including complex cardiopathy. The boy died in the neonatal period. $H$ heart, $R L$ right lung 

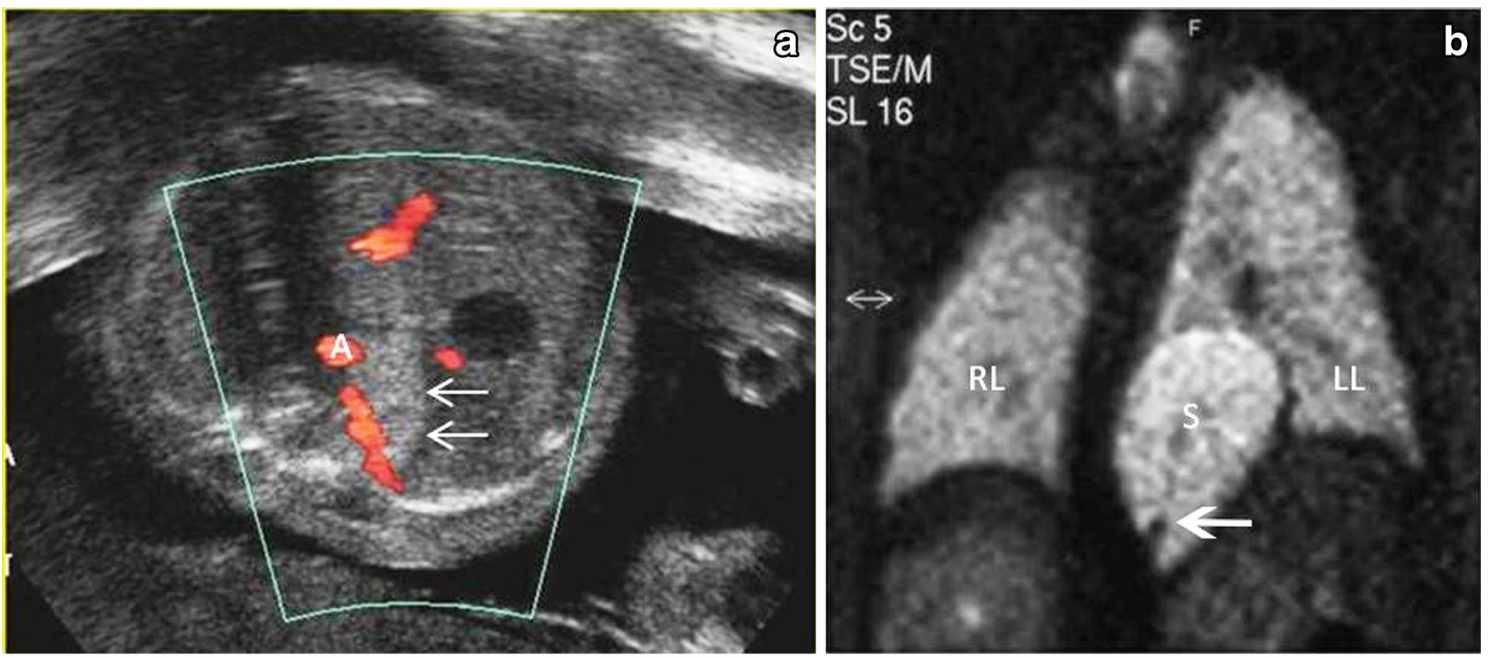

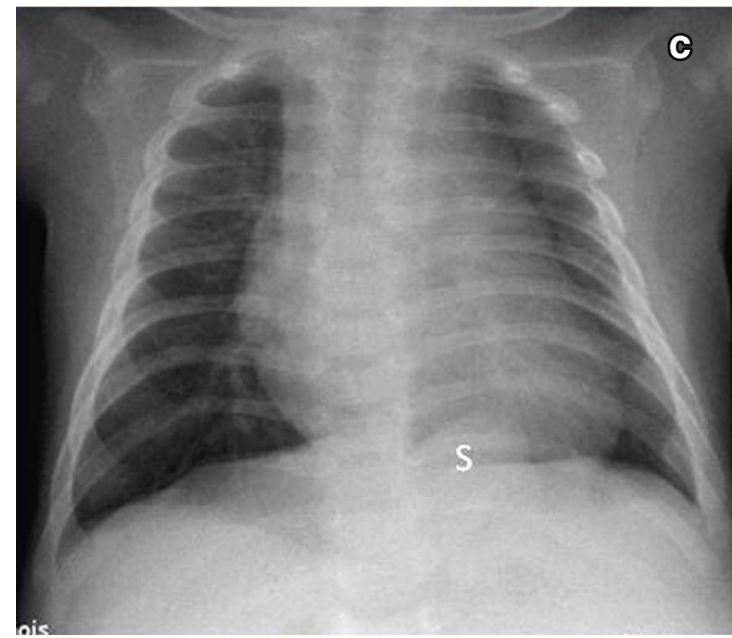

Fig. 9 Left diaphragmatic extralobar pulmonary sequestration. a Transverse Doppler US image obtained at 24 weeks of gestation at the level of the diaphragm shows a hyperechogenic left paramedian lesion (arrows) with anomalous vascularization arising from the abdominal aorta $(A)$. b Coronal T2-W MR image confirms the lung sequester $(S)$, which is hyperintense related to the normal right lung $(R L)$ and left lung $(L L)$, and its anomalous vascular supply (arrow). c, d Neonatal

\section{Tumoral pathology}

Congenital tumors only represent $1.5-2 \%$ of all pediatric tumors, with a prevalence of $1: 12,500$ to $1: 27,500$ live births. Most of them are first diagnosed after birth, with a small number of cases detected in the last trimester of pregnancy. The diaphragm is exceptionally the primary organ of origin. A review of the literature shows only one case of a primary diaphragmatic rhabdomyosarcoma detected in utero [5]. Some cases of secondary infiltration by tumors originating from an adjacent organ have been reported during the third trimester of gestation, mainly mediastinal teratomas and pleuro-pulmonary blastomas [57].

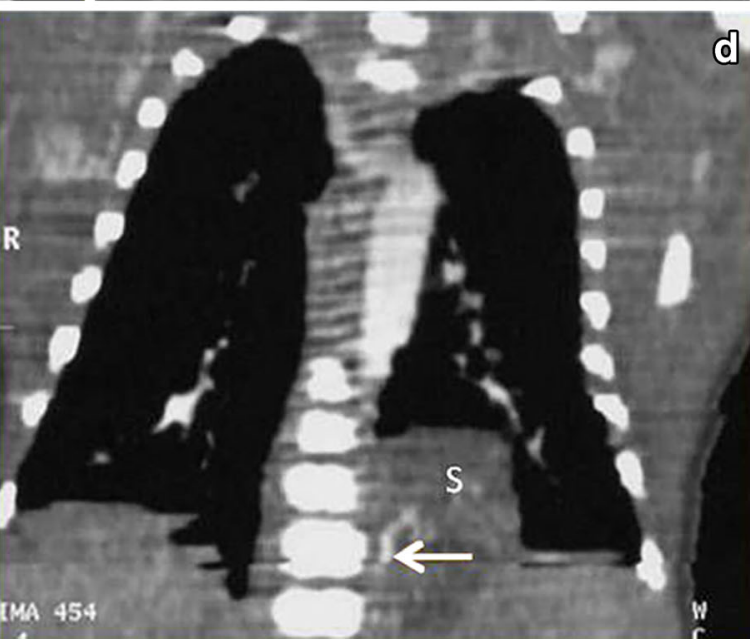

anteroposterior chest radiograph (c) and coronal reconstruction of intravenous-contrast-enhanced postnatal chest CT scan obtained at 4 weeks (d) show the not-ventilated left thoracic basal lesion $(S)$ and its systemic vascular supply. A diaphragmatic-located extralobar pulmonary sequestration was identified at surgery and confirmed at pathology (Images courtesy of Guy Sebag and Nadia Belarbi, Robert-Debré Hospital, Paris, France)
The pericardium is the anatomical origin for most mediastinal teratomas. They are often associated with pericardial effusion. Pleuro-pulmonary blastoma is a primary mesenchymal tumor that usually appears as a heterogeneous, rapidly growing mass, predominantly cystic and often associated with pleural effusion. We have prenatally detected a secondary tumoral diaphragmatic infiltration at our institution. The tumor was first observed at routine US at the 22nd week of gestation. It was well-defined and solid-appearing and caused pleural effusion. Infiltration of the diaphragm was suspected at prenatal MRI performed at the 24th week because of irregular tumor borders and thickening of the diaphragm in contact with the tumor (Fig. 10). Pregnancy was terminated because of rapid growing of the lesion. A pleuropulmonary blastoma 

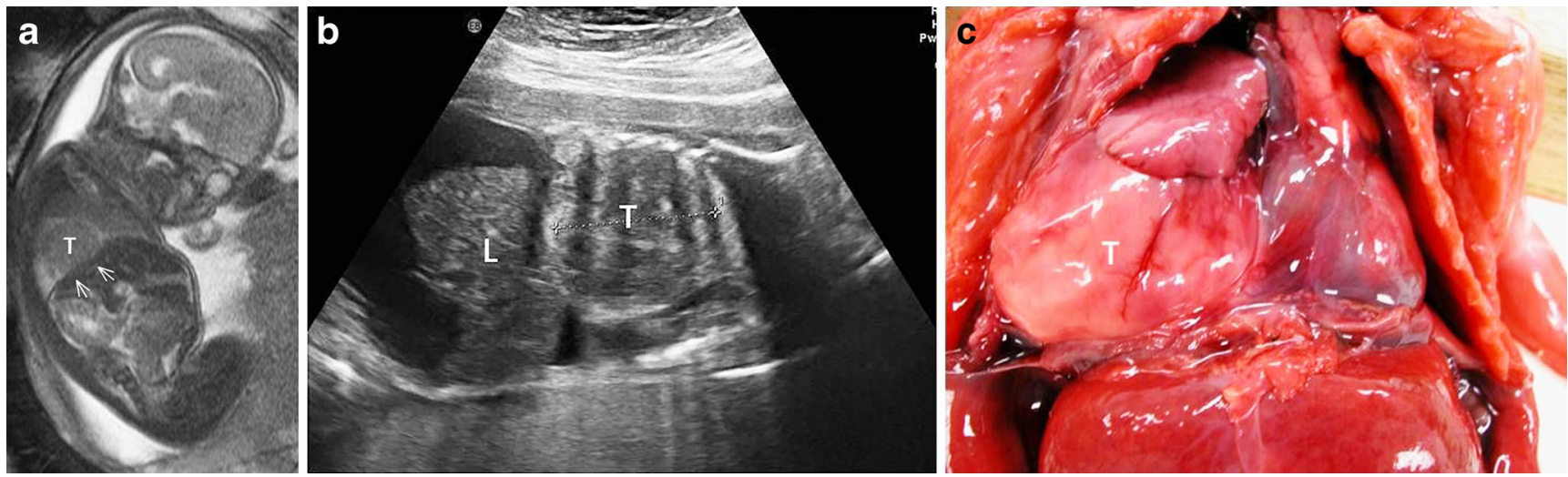

Fig. 10 Right pleuropulmonary blastoma with secondary infiltration of the diaphragm in a female fetus. a The right parasagittal T2-W MR image obtained at 24 weeks of gestation shows the solid tumor $(T)$ at the right hemithorax base with associated pleural effusion. b Sagittal US image obtained several days later shows increasing pleural effusion and

with secondary infiltration of the diaphragm was confirmed at pathology.

\section{Conclusion}

Congenital pathologies of the diaphragm are increasingly detected as consequence of the extension of prenatal screening imaging US studies and complementary MRI exams. An appropriate knowledge of the embryology of the diaphragm is crucial to understand both its pathology and the consequences on the developing lungs. Congenital diaphragmatic hernia is by far the most commonly observed pathology, but diaphragmatic eventration, paralysis, diaphragmatic located extralobar lung sequestrations and primary or secondary tumoral infiltration of the diaphragm might also be detected in utero. Knowledge of the typical imaging findings of these entities can help radiologists to adequately identify the pathology. Diaphragmatic defects are associated with high postnatal morbidity and mortality. Predictors of postnatal outcome based on prenatal imaging have been developed. Radiologists should know both these indexes and their limits in predicting outcome after birth.

\section{Conflicts of interest None}

\section{References}

1. Tovar JA (2012) Congenital diaphragmatic hernia. Orphanet J Rare Dis $7: 1$

2. Stege G, Fenton A, Jaffray B (2003) Nihilism in the 1990s: the true mortality of congenital diaphragmatic hernia. Pediatrics 112:532 535

3. Jurcak-Zaleski S, Comstock CH, Kirk JS (1990) Eventration of the diaphragm: prenatal diagnosis. J Ultrasound Med 9:351-354 development of ascites. Pregnancy was terminated at the 27th week. c Macroscopic imaging of the fetal specimen with opened thorax shows the voluminous solid tumor and the enlarged focal diaphragm in contact with the lesion. Infiltration of the diaphragm was confirmed at pathology. $L$ liver, $T$ tumor

4. Berrocal T, Madrid C, Novo S et al (2004) Congenital anomalies of the tracheobronchial tree, the lung and the mediastinum. Radiographics 24:e17

5. Reitter A, Peters J, Wittekind B et al (2012) Prenatal management of diaphragmatic rhabdomyosarcoma presenting with fetal hydrops. Ultrasound Obstet Gynecol 40:235-237

6. Barth RA (2012) Imaging of foetal chest masses. Pediatr Radiol 42 $62-73$

7. Alamo L, Reinberg O, Vial Y et al (2013) Comparison of foetal US and MRI in the characterisation of congenital lung anomalies. Eur $\mathrm{J}$ Radiol 82:860-866

8. Recio Rodriguez M, Martinez de Vega V, Cano Alonso R et al (2012) MR imaging of thoracic abnormalities in the fetus. Radiographics 32:E305-E321

9. Taybi H, Lachmann RS (2007) Radiology of syndromes, metabolic disorders and skeletal dysplasias. Mosby Elsevier, St. Louis

10. Mehollin-Ray AR, Cassady CI, Cass DL et al (2012) Fetal MR imaging of congenital diaphragmatic hernia. Radiographics 32: 1067-1084

11. Chavhan GB, Babyn PS, Cohen RA et al (2010) Multimodality imaging of the pediatric diaphragm: anatomy and pathologic conditions. Radiographics 30:1797-1817

12. Moore KL, Persaud TVN (2008) Before we are born: essentials of embryology and birth defects. Saunders Elsevier, Philadelphia

13. Nason LK, Walker CM, McNeely MF et al (2012) Imaging of the diaphragm: anatomy and function. Radiographics 32: E51-E70

14. Restrepo CS, Eraso A, Ocazionez D et al (2008) The diaphragmatic crura and retrocrural space: normal imaging appearance, variants and pathologic conditions. Radiographics 28:1289-1305

15. Zankl A, Osterheld MC, Vial Y et al (2007) Right-side diaphragmatic eventration: a rare cause of non-inmune hydrops fetalis. Neonatology 92:14-18

16. Taylor GA, Atalabi OM, Estroff JA (2009) Imaging of congenital diaphragmatic hernias. Pediatr Radiol 39:1-16

17. Skandalakis JE, Gray SW, Ricketts RR (1994) The diaphragm. In: Skandalakis JE, Gray SW (eds) Embryology for surgeons, 2nd edn. Williams and Wilkins, Baltimore, pp 491-539

18. Stolar CJH (1997) Congenital diaphragmatic hernia. In: Oldham KT, Colombani PM, Foglia RP (eds) Surgery of infants and children: scientific principles and practice. Lippincott-Raven, Philadelphia, pp 883-895

19. Iritani I (1984) Experimental study on embryogenesis of congenital diaphragmatic hernia. Anat Embryol 69:133-139 
20. Mayer S, Metzger R, Kluth D (2011) The embryology of the diaphragm. Semin Pediatr Surg 20:161-169

21. Butler N, Claireaux AE (1962) Congenital diaphragmatic hernia as a cause of perinatal mortality. Lancet 1:659-663

22. Comstock C, Bronsteen RA, Whitten A et al (2009) Paradoxical motion: a useful tool in the prenatal diagnosis of congenital diaphragmatic hernias and eventrations. J Ultrasound Med 28:13651367

23. Kotecha S, Barbato A, Bush A et al (2012) Congenital diaphragmatic hernia. Eur Respir J 39:820-829

24. Barnewolt CE, Kumisaki SM, Fauza DO et al (2007) Percent predicted lung volumes as measured on fetal MRI: a useful biometric parameter for risk stratification in congenital diaphragmatic hernia. J Pediatr Surg 42:193-197

25. Gorincour G, Evrin D, Avni FE (2007) Prenatal detection of pulmonary hypoplasia: US and MRI working together. Radiology 245: 608-609

26. Mullassery D, Ba'ath ME, Jesudason DC et al (2010) Value of liver herniation in prediction of outcome in fetal congenital diaphragmatic hernia: a systematic review and meta-analysis. Ultrasound Obstet Gynecol 35:609-614

27. Jani JC, Cannie M, Peralta CFA et al (2007) Congenital diaphragmatic hernia: comparison of 3D US and MR imaging assessments. Radiology 244:575-582

28. Metkus AP, Filly RA, Stringer MD et al (1996) Sonographic predictors of survival in fetal diaphragmatic hernia. J Pediatr Surg 31: 148-151

29. Ba'ath ME, Jesudason EC, Losty PD (2007) How useful is the lung-to-head ratio in predicting outcome in the foetus with congenital diaphragmatic hernia? A systematic review and meta-analysis. Ultrasound Obstet Gynecol 30:897-906

30. Jani JC, Benachi A, Nicolaides KH et al (2009) Prenatal predictors of neonatal morbidity in survivors with congenital diaphragmatic hernia: a multicenter study. Ultrasound Obstet Gynecol 33:64-69

31. Kehl S, Kalk AL, Eckert S et al (2011) Assessment of lung volume by 3-dimensional sonography and MRI in fetuses with $\mathrm{CDH}$. J Ultrasound Med 30:1539-1545

32. Rypens F, Metens T, Rocourt N et al (2001) Fetal lung volume: estimation at MR imaging — initial results. Radiology 219:236241

33. Debus A, Hagelstein C, Kilian AK et al (2012) Fetal lung volume in congenital diaphragmatic hernia: association of prenatal MR imaging findings with postnatal chronic lung disease. Radiology 266 : 887-895

34. Cannie M, Jani J, Meersschaert J et al (2008) Prenatal prediction of survival in isolated diaphragmatic hernia using observed to expected total fetal lung volume determined by MRI based on either gestational age or fetal body volume. Ultrasound Obstet Gynecol 32:633-639

35. Cannie M, Cordier AG, Laveaucoupet J et al (2012) Liver to thoracic volume ratio: use at MR imaging to predict postnatal survival in fetuses with isolated congenital diaphragmatic hernia with or without prenatal tracheal occlusion. Eur Radiol 23:1299-1305

36. Mayer S, Klaritsch P, Petersen S et al (2011) The correlation between lung volume and liver herniation measurements by fetal MRI in isolated congenital diaphragmatic hernia: a systematic review and meta-analysis of observational studies. Prenat Diagn 31: 1086-1096

37. Hedrik HL, Danzer E, Merchant A et al (2007) Liver position and lung-to-head ratio for prediction of extracorporeal membrane oxygenation and survival in isolated left congenital diaphragmatic hernia. Am J Obstet Gynecol 197:422.e1-e4
38. Suda K, Bigras JL, Bohn D et al (2000) Echographic predictors of outcome in newborns with congenital diaphragmatic hernia. Pediatrics 105:1106-1109

39. Garne E, Haeusler M, Barisic I et al (2002) Congenital diaphragmatic hernia, evaluation of prenatal diagnosis in 20 European regions. Ultrasound Obstet Gynecol 19:329-333

40. Seaward GR (2005) The fetal chest. In: Rumack CM, Wilson SR, Charboneau JS (eds) Diagnostic ultrasound, 3rd edn. Elsevier Mosby, St. Louis, pp 1303-1321

41. Koziarkiewicz M, Taczelska A, Piasezna-Piotrowska A (2013) Long-term follow-up in children with congenital diaphragmatic hernia: observations from a single institution. Eur J Pediatr Surg 24:500-507

42. Coleman A, Phithakwatchara N, Shaaban A et al (2015) Fetal lung growth represented by longitudinal changes in MR-derived fetal lung volume parameters predicts survival in isolated left-sided congenital diaphragmatic hernia. Prenat Diagn 35:160-166

43. Zöllner FG, Zahn K, Schible T et al (2012) Quantitative pulmonary perfusion imaging at $3.0 \mathrm{~T}$ of 2-year-old children after congenital diaphragmatic hernia repair: initial results. Eur Radiol 22:27432749

44. Balassy C, Kasprian G, Brugger P et al (2009) Assessment of lung development in isolated congenital diaphragmatic hernia using signal intensity ratios on fetal MR imaging. Eur Radiol 20:829-837

45. Vuletin JF, Lim FY, Cnota J et al (2010) Prenatal pulmonary hypertension index: novel prenatal predictor of severe postnatal pulmonary artery hypertension in antenatally diagnosed congenital diaphragmatic hernia. J Pediatr Surg 45:703-708

46. Deprest J, Gratacos E, Nikolaides KH (2004) FETO task group. Ultrasound Obstet Gynecol 24:121-126

47. Deprest J, Jani J, Gratacos E et al (2005) Fetal intervention for congenital diaphragmatic hernia: the European experience. Semin Perinatol 29:94-103

48. Osborn AJ, Baud D, Macarthur AJ et al (2013) Multidisciplinary perinatal management of the compromised airway on placental support: lessons learned. Prenat Diagn 33:1-8

49. Mychaliska JB, Bealer JF, Flake AW et al (2001) The EXIT procedure: experience and outcome in 31 cases. J Pediatr Surg 37:418426

50. Barlett RH, Gazzaniga AB, Toomasian J et al (1986) Extracorporeal membrane oxygenation (ECMO) in neonatal respiratory failure. Ann Surg 204:236-245

51. Mugford M, Elbourne D, Field D (2008) Extracorporeal membrane oxygenation for severe respiratory failure in newborn infants. Cochrane Database Syst Rev 3, CD001340

52. Reiss I, Schaible T, van der Hout L et al (2010) Standarized postnatal management of infants with congenital diaphragmatic hernia in Europe: the CDH EURO consortium consensus. Neonatology 98:354-364

53. Kinsella JP, Parker TA, Ivy DD et al (2003) Noninvasive delivery of inhaled nitric oxide therapy for late pulmonary hypertension in newborn infants with congenital diaphragmatic hernia. J Pediatr 142:397-401

54. Nijagal A, Jelin E, Feldstein VA et al (2012) The diagnosis and management of intradiaphragmatic extralobar pulmonary sequestrations: a report of 4 cases. J Pediatr Surg 47:1501-1505

55. Escobar MA, Acierno SP (2012) Laparoscopic resection of an intradiaphragmatic pulmonary lung sequestration: a case report and review of the literature. J Pediatr Surg 47:2129-2133

56. Meier AH, Eggli KD, Cilley RE (2001) Intradiaphragmatic extralobar sequestration - a rare pulmonary anomaly. J Pediatr Surg 36:784-790

57. Alamo L, Beck Popovic M, Gudinchet F et al (2011) Congenital tumors: imaging when life just begins. Insights Imaging 2:297-308 